\title{
Crianças no mundo do trabalho adulto: a História de Grilo e as memórias de infâncias perdidas (Recife, 1920-1930)
}

\author{
Humberto Silva Miranda*
}

humbertoufrpe@gmail.com

\begin{abstract}
Resumo
Este artigo objetiva debater o cotidiano das crianças no mundo do trabalho, no Recife das décadas de 1920 e de 1930. A trajetória de Grilo - apelido de criança do político pernambucano Gregório Bezerra, que viveu nas ruas da capital pernambucana neste período -, será o fio condutor desta trama. Em nome do "progresso", Gregório e outras crianças se inseriram no mundo do trabalho dos adultos, sobrevivendo a diferentes desafios cotidianos, marcado pela violência e injustiças sociais. Gregório, João, Maria, Francisco e outros meninos e meninas são agentes sociais que fazem parte desta trama, que procura colocar em tela a história de crianças que foram desafiadas a sobreviver aos diferentes modos de exploração imposta pelos interesses dos adultos. Por meio da análise dos relatos de memórias, dos recortes de jornais e de outras fontes buscamos produzir a história do Recife a partir das trajetórias de vida desses meninos e meninas. É neste cenário urbano que diferentes vidas se encontraram para vivenciar e sobreviver às diferentes formas de abandono e de exploração do trabalho.
\end{abstract}

\section{Palavras chaves}

Crianças; trabalho; Recife

\section{Children in the world of adult work: the History of Grilo and the memories of lost childhoods (Recife, 1920-1930)}

\begin{abstract}
This article aims to discuss the daily life of children in the world of work in Recife in the 1920s and 1930s. The trajectory of Grilo - the nickname of a child of the Pernambuco politician Gregório Bezerra, who lived on the streets of the city of Pernambuco during this period will be the conductor wire of this frame. In the name of progress, "Gregory and other children joined the world of adult work, surviving different daily challenges, marked by violence and social injustice. Gregorio, João, Maria, Francisco and other boys and girls are social agents that are part of this plot, which seeks to screen the history of children who were challenged to survive the different modes of exploitation imposed by the interests of adults. Through the analysis of reports of memories, newspaper clippings and other sources, we seek to produce the history of Recife from the life trajectories of these boys and girls. It is in this urban scenario that different lives have met to experience and survive the different forms of abandonment and exploitation of work.
\end{abstract}

\section{Keywords}

Children; work; Recife

*Doutor em História pela Universidade Federal de Pernambuco (UFPE). Professor do Departamento de Educação da UFRPE. Professor do Programa de Pós-Graduação em História da UFRPE e do Programa Educação, Culturas e Identidades (UFRPE/Fundaj). 


\section{A trajetória de Grilo: entre (des)encontros fugas}

O pequeno Grilo chegou ao Recife. O seu desembarque foi na Estação das Cinco Pontas. Naquela noite, o Recife estava iluminado por velhos lampiões a gás o que o fez lembrar-se "do reino encantado das estórias" contadas pela sua avó. Contudo, o encanto foi-se perdendo, uma vez que, lá mesmo na estação, Grilo se encontrou com pessoas doentes, dormindo nas calçadas, pedindo esmolas e com outros sinais que evidenciavam as contradições sociais da cidade.

Assim, na construção das memórias de si, o político pernambucano Gregório Bezerra - já adulto -, relatou a trajetória do pequeno Grilo e o seu primeiro encontro com a cidade, marcado pelo desencanto:

Para mim foi um desastre. Eu tinha impressão de que a cidade do Recife era uma cidade só de rico, que não existia ninguém pobre, não havia ninguém pedindo esmolas, não existiam miseráveis; e logo na estação vi uma porção de gente doente, exibindo as feridas das pernas, os aleijões, as deformações de toda natureza. Eu fiquei horrorizado. Nunca pensei que em Recife também tivesse gente doente, gente miserável como nós (FERNANDES, 1982).

As memórias de Gregório Bezerra sobre sua chegada ao Recife tornam-se um documento valioso para o historiador que procura entender a cidade e suas contradições sociais. O Recife desenhado por Gregório, foi colocado em tela a partir do seu desencanto.

A construção de uma cidade "ideal" para viver foi desconstruída no primeiro instante, no primeiro olhar, uma vez que, ao desembarcar no Forte das Cinco Pontas, o pequeno Grilo se deparou com a cidade das desigualdades sociais. Assim narrou Gregório Bezerra - já adulto -, o seu primeiro encontro com o Recife.
Gregório descreveu: "na cidade dos meus encantos havia muita pobreza, miséria e sofrimento...".

Ao narrar suas memórias do tempo de criança, Gregório desenhou o olhar de uma criança sobre o Recife marcado pelo estranhamento, ao encontrar tanta gente pedindo esmola e vivendo diferentes condições de pobreza, expondo suas "feridas". Os relatos de memórias do Gregório - que fez construir o nosso Grilo -, buscou relatar o cenário do Recife a partir do sentimento da decepção e horror.

Ao publicar suas memórias, Gregório Bezerra nos deixou um importante registro de sua atuação política e de sua trajetória de vida (BEZERRA, 1979). Na parte dedicada à infância, o político pernambucano Gregório Bezerra passou a relatar seu cotidiano no Recife, vivenciado durante as primeiras décadas do século XX. Nesse "teatro da memória", na qual Gregório foi o personagem de si mesmo, percebemos que a escrita autorreferecial, ou escrita de si, foi construída à luz das práticas e posições políticas vivenciadas pelo autobiografado.

A luta no Partido Comunista e a influência do pensamento marxista, por exemplo, estão fortemente presentes na sua narrativa, fazendo com que as questões políticas por ele vividas se entrelaçassem com as suas memórias de infância e juventude. Ao trabalharmos com autobiografias, temos que analisar o que está "por trás do texto", onde temos que buscar a relação entre o "mundo" e o "eu" do autobiografado (GOMES, 2004).

A escrita autobiográfica, enquanto fonte para escrita da história, leva-nos a conhecer os fatos e acontecimentos à luz das lembranças do depoente. Essas lembranças não devem ser analisadas distante do lugar social e político ao qual o biografado pertence. Desse modo, também não podemos negligenciar outras formas subjetivas, presentes na narrativa do entrevistado, 
como os medos, as angústias e os anseios (LE GOFF, 2000).

Ao discutir a relação da historiografia com a documentação autobiográfica, Ângela de Castro Gomes afirma que o historiador deve considerar a questão da "ilusão biográfica", criticando a existência de um "eu" coerente e contínuo, para que não sejam reproduzidos os "efeitos de verdade" expressados na narrativa autobiográfica (GOMES, 2004). Ao se debruçar sobre uma escrita autorreferencial, o historiador dialoga com as novas perspectivas historiográficas, quando a memória individual passa a ser utilizada como fonte documental para a construção da escrita história. Ainda de acordo com Gomes, os registros de memórias são uma prática bastante característica do "homem moderno", em que são:

De forma geral e por definição, subjetivos, fragmentados e ordinários como suas vidas. Seu valor, especialmente como documento histórico, é identificado justamente nessas caracteristicas, e também em uma qualidade decorrente de uma nova concepção de verdade, própria às sociedades individualistas. Sociedades que separam o espaço público do privado, a vida laica da religiosa, mas que, em todos os casos, afirmaram o triunfo do individuo como sujeito voltado para si, para sua razão e seus sentimentos. Uma sociedade em cuja cultura importa aos indivíduos sobreviver na memória dos outros, pois a vida individual tem valor e autonomia em relação ao todo. É dos individuos que nasce a organização social e não o inverso (GOMES, 2004, p.13).

Escrever história a partir de documentos autobiográficos exige do historiador o compromisso com a criticidade. Desse modo, ao nos voltarmos sobre a escrita de Gregório Bezerra, uma escrita de si, estamos ouvindo a voz de um ex-militante comunista, que enfrentou os embates, as divergências dos setores mais conservadores da política brasileira e do próprio Partido Comu- nista. O que nos interessa ao nos voltarmos sobre a escrita autobiográfica de Gregório Bezerra, não "se trata de dizer o houve, mas de dizer o que o autor diz que viu, sentiu, experimentou”. Desse modo, vamos lá!

Gregório Lourenço Bezerra nasceu em Panelas de Miranda, Pernambuco, em 13 de março de 1900. Filho de Lourenço Bezerra do Nascimento e de Belarmina Conceição do Nascimento, camponeses pobres, analfabetos, que enfrentaram nas suas vidas os problemas causados pelos problemas econômicos típicos dos sertões nordestinos: seca, desemprego, entre outros... Serviu ao Exército, pertenceu às fileiras do Partido Comunista e foi parlamentar, tornando-se uma liderança bastante conhecida por sua militância, chegando a participar dos dois momentos ditatoriais estabelecidos no Brasil republicano.

Todavia, poucos conhecem a história da sua infância e juventude, momentos de sua vida que nos possibilitam uma melhor compreensão acerca de sua trajetória pessoal e política. Nesse trabalho nos voltaremos para a história de Grilo, como era chamado Gregório Bezerra, quando criança. O codinome Grilo faz referência a seu porte físico, uma vez que era um garoto franzino, baixinho e que possuía grandes olhos azuis.

Aos nove anos de idade, foi visitar sua irmã, que morava em Palmares. Chegando lá, conheceu Dona Dondom, esposa do Senhor Magalhães, proprietário do Sítio Brejinho, que ficou interessada em levá-lo para o Recife, uma vez que gostou dos trabalhos que havia realizado na horta da casa de uma das madrinhas de suas irmãs. A promessa de ensiná-lo a "ler, a escrever e a contar", animou o menino Gregório, que aceitou o convite.

As lembranças da viagem para o Recife, não se perderam no tempo. Na vinda para a cidade grande, "era uma grande admiração pelo que via. Os morros, os rios, as pontes, os canaviais, as usinas às margens das 
cidades (...). Uns com os sacos nos ombros, chapéu de palha na cabeça, barbas crescidas, descalços, na maioria desdentados..." (BEZERRA, 1979, p.96). Era um trem que transportava os passageiros inseridos na categoria denominada como "segunda classe". Era o povo. Muitos podiam morar no Recife, outros provavelmente iriam visitar os parentes que lá se encontravam. Cada um com um destino. E o de Grilo, qual seria?

Tudo aquilo para ele era estranho. Grilo se encontrava com o novo. Os trabalhos domésticos da casa dos Magalhães passaram a fazer parte do seu dia a dia e, a partir deles, o menino do Sertão passou a conhecer o Recife. Realizando suas obrigações, a pedido de seus responsáveis, visitava a farmácia do Doutor Tomé Gibson, "na Rua São João com o Pátio do Terço"; a Cruz Vermelha, uma firma de importação e exportação, localizada na Praça da Estação central e outros cantos e recantos da cidade que Grilo passou a conhecer através dos recados, das entregas ou busca das encomendas, passando, inclusive, a conviver com as pessoas dos arredores.

A promessa de alfabetizá-lo nunca foi cumprida. Contudo, teve que aprender a rezar. Não era do seu agrado, "mas a disciplina doméstica" o obrigava. A jornada de trabalho diário se tornava mais pesada e o sonho com aprender a "ler, escrever e contar" se tornava mais distante. Ao narrar suas memórias, Gregório nos fala dos seus sentimentos, entre eles, o da frustração, da angústia e até mesmo do ódio, haja vista que, no decorrer de suas andanças pela cidade, Grilo percebeu que outras crianças brincavam e se divertiam, enquanto ele não vivia esses momentos. Ao relatar as suas relações com um colega que também trabalhava na casa dos Magalhães e com outras crianças, recordava: homens. Crianças que morriam de fome, viviam descalças e não tinham casas para morar; crianças, enfim, que nada tinham e apenas vegetavam com os seus pais, e muitas nem pais possuíam. Eu tinha saudade de minha mãe, de meus irmãos, de vovó, de meus tios e chorava nas horas de maior aflição. Nós tínhamos tempo de conversar na hora de dormir e muito baixo para não incomodar os nossos senhores, donos da vida (BEZERRA, 1979, p. 102).

Nas suas memórias, Gregório nos relata como era vivido o cotidiano das crianças que circulavam ou até moravam nas ruas comerciais do Recife e que se encontravam no contexto de abandono e pobreza. Este momento sócio-histórico marca o surgimento das primeiras iniciativas do Estado no sentido construir um plano político-jurídico de assistência à infância. A presença dessas crianças e jovens, nas ruas dos centros grandes urbanos, inclusive do Recife, passou a comprometer a segurança e a comodidade daqueles que transitavam nesse espaço comercial, comprometendo o projeto econômico da sociedade burguesa e do cotidiano daqueles que tinham esses espaços como locais de lazer.

A fuga se apresentou como alternativa para sair da casa dos Magalhães. Ao fugir, a rua se tornou o local da sua morada. Na rua, Grilo encontrou outras crianças que buscavam sobreviver no mundo da pobreza e do abandono. Muitos trabalhavam de dia e voltavam à noite para suas casas, outros permaneciam nas ruas, pois eram nos becos, nas esquinas, nas calçadas que elas dormiam... Ao estudar a questão das crianças que viviam nas ruas das grandes cidades durante as primeiras décadas dos novecentos, a historiadora Esmeralda Moura nos fala que naquele período a rua apresentavase como um local de múltiplas identidades, quando: 
ada. A rua é, também, o espaço no qual a pobreza ganha plena visibilidade, mesclando-se à tão questionada marginalidade social, e são tênues os limites que a separam do crime e da delinquência com os quais frequentemente se confunde (MOURA, 1999, p. 95).

Nas ruas, essas crianças buscavam, das mais diferentes formas, resistir aos desafios que lhes eram impostos. Foi o que aconteceu com Grilo, que trabalhou como freteiro, pediu esmolas e prestou pequenos serviços em troca de comida ou de um local para dormir. Muitas dessas crianças tinham na rua como uma "grande escola", onde nela lhes eram ensinadas as grandes lições de como enfrentar os perigos da rua.

$\mathrm{Na}$ construção das memórias de si, Gregório narrou as fugas como práticas de resistência produzida por um menino. A trajetória do pequeno Grilo, marcada pela exploração do trabalho doméstico, pela negação do direito de estudar e pelas expectativas não correspondidas, das promessas não cumpridas fazem parte de um discurso "sobre si", acerca daquele que desde pequeno aprendeu a ser "revolucionário".

\section{Grilo não estava só. Maria, Augusto e outras crianças}

No decorrer da nossa investigação, percebemos que Grilo não estava só. Naquele período, as notas de jornais denunciavam as fugas de meninos e meninas do Recife, quando muitos deles também buscaram escapar dos trabalhos domésticos, como foi o caso de Simplício Gomes, de 13 anos de idade, que era empregado na residência de Maria Amélia. Em janeiro de 1930, Simplício recebeu "20\$000 para fazer umas compras, não mais voltou”. Maria Amélia apresentou-se na polícia para prestar queixa contra o garoto. A nota do Jornal do Commercio trazia o título: "um menor que promete, saiu e errou o caminho da volta" (JORNAL DO COMMÉRCIO, 1930).

Em 8 de janeiro de 1931, o Diário de Pernambuco trazia outra notícia de desaparecimento de criança. Maria de Barros também fugiu da casa do Senhor Eduardo Lima. Dizia a nota:

\begin{abstract}
Menor desaparecida
Era empregada na casa de família do $\mathrm{Sr}$. Eduardo Lima, à rua da Concórdia nesta cidade, a menor Maria de Barros, de 15 annos de idade de cor branca (...). Sendo natural deste Estado, com a família de Garanhuns, fugiu ante-hontem da casa onde se achava tomando destino ignorado. O caso foi levado ao conhecimento da polícia para devidas providências (DIÁRIO DE PERNAMBUCO a, 1931).
\end{abstract}

A pequena notícia de jornal ainda trazia a informação que Maria de Barros trabalhava na casa daquela família desde os 8 anos de idade. Um mês depois, daquele mesmo ano, o Diário de Pernambuco trazia um outro caso, desta vez o de Maria de Lima, que fugiu da casa dos patrões na manhã do dia 12 de fevereiro. Maria de Lima era branca, tinha 14 anos de idade e trabalhava como doméstica na casa de João Alves de Mello e de Luiza de Souza Mello. Dizia o jornal que "a referida menor é natural de Alagoas e vive na casa daquela família a cerca de 8 anos" (Diário de Pernambuco b, 1931). Assim como os patrões de Maria de Barros, a família Mello também foi prestar queixa no Primeiro Distrito da Capital.

Maria de Barros, Maria de Lima e tantas outras "marias"... A escapada das meninas, assim como a de Gregório e a de Simplício, da casa dos patrões - que pode ser vista como uma tática, com a qual as crianças desafiaram a estratégia dos adultos. De acordo com Michel de Certeau, a tática pode ser considerada como a "arte do fraco", determinada pela "ausência de poder", 
sendo vivida nas sutilezas do convívio social. Para Certeau:

A tática não tem o lugar senão o do outro. E por isso deve jogar com o terreno que lhe é imposto tal como o organiza a lei de uma força estranha. Não tem meios para se manter em si mesma, à distancia, numa posição recuada, de previsão e de convocação própria: a tática é o movimento dentro do campo de visão do inimigo e no espaço por ele controlado (CERETAU, 1994, p. 101).

A tática é a "vitória do fraco contra o forte", assim nos diz Certeau. Diferente das estratégias, as táticas são construídas nas práticas cotidianas, quando as artes de falar, escrever, circular, ocupar e até mesmo a arte de fugir se apresentam como os mais variados tipos de táticas. Grilo, Simplício e as Marias desafiaram o olhar panóptico da sociedade que viviam e fugiram para um outro lugar, para um outro mundo, onde buscaram desafiar os obstáculos impostos pela vida. A história de cada um desses agentes nos mostra que, frente aos sistemas de disciplina, existe a indisciplina, frente aos mecanismos de ordem, existe a desordem e frente as estratégias de controle, existe a busca pela liberdade.

Mas, a história de fugas dos nossos protagonistas não para por aqui. Nossa investigação nos aponta que várias crianças fugiam das "garras" dos patrões e também do convívio familiar, como foi o caso de Antonio dos Santos, um garoto de 12 anos, que desapareceu da casa dos pais, em março de 1929 (JORNAL DO COMÉRCIO b, 1929). No ano seguinte, em 18 de janeiro de 1931, o Diário de Pernambuco trazia a notícia de um outro caso: Priscila Campelo tinha sido encontrada, a menor de 17 anos tinha fugido da casa de seu pai adotivo. Assim dizia a nota:
Há dias desapareceu da residência do seu pai adotivo, à rua de Jangada, $n^{\circ} 59$, em São José, a menor de 17 annos Priscilla Campello, orphã de pai e mãe. O senhor por isso compareceu à $3^{a}$ delegacia apresentando queixa. Hontem pela manhã, a menor alludida foi encontrada na casa de uma viúva à rua Nova Seita, $n^{\circ}$ 120, em Campo Grande, para onde tinha fugido. A polícia do $3^{\circ}$ distrito está ciente do facto e a menor será apresentada ao juiz de órfãos (DIÁRIO DE PERNAMBUCO c, 1931).

Priscila era órfã de pai e mãe e vivia com seu pai adotivo no Bairro de São José. Nesse caso, a menor foi encaminhada ao Juiz de Órfãos, a fim de ser acompanhada por aquela autoridade da Justiça. A pequena nota traz uma informação importante: a intervenção do sistema jurídico no caso da menor. Os vários casos anteriores, que envolviam o desaparecimento das crianças, eram resolvidos na delegacia, levando-nos a perceber que, no Brasil, os problemas sociais referentes às crianças e jovens que viviam em situação limite se tornavam “casos de polícia”. Com a promulgação do Código de Menores de 1927, esses casos, mesmo sendo recorridos na primeira instância ao aparato policial, passavam a ser encaminhados para o Juiz de Menores ou o Juiz de Órfãos, como foi o caso da Priscila.

No Código de Menores de 1927, o espaço destinado à questão da relação entre pais e filhos ou responsáveis, mereceu um capítulo especial e esteve voltado para a preocupação com "a inibição do pátrio poder e da remoção da tutela". Em nome "da honra e da honestidade das famílias", o discurso do Código foi construído a partir da premissa do controle e da punição dos pais, mães ou tutores que desrespeitassem os ditos daquele instrumento normatizador.

Nesse sentido, o papel social do pai, da mãe ou do tutor estava relacionado à garantia de uma assistência econômica, social e psicológica, cujas as relações entre pais e filhos passaram a ser pautadas do campo 
dos sentimentos, quando o lar passou a representar o espaço onde esses aspectos deveriam ser harmonicamente vivenciados. Ao nos voltarmos para o Artigo 31, Capítulo V do Código de Menores de 1927 verificamos que:

Nos casos em que aprovada negligência a incapacidade, o abuso de poder, os maus exemplos, a crueldade, a exploração, a perversidade, ou o crime do pai da mãe ou do tutor podem comprometer a saúde, segurança ou moralidade do filho ou do pupilo, a autoridade competente decretará a suspensão ou a perda do pátrio poder ou a destituição da tutela, como no caso couber (BRASIL, 1927).

Analisando esse trecho do Código, podemos perceber que o seu discurso dialoga com o novo sentimento de família, quando o Estado, revestido de sua "autoridade", passava a ter controle e poder de punição sobre os pais ou responsáveis, que, por sua vez, atendia à manutenção e ao fortalecimento do direito penal moderno, no qual a prevenção e a punição passaram a dialogar de forma efetiva. A partir desse princípio, a proposta do Código era de estabelecer uma nova lógica de poder entre o Estado e as famílias, uma vez que esse buscava intervir diretamente no campo das relações domésticas, transferindo para si a "autoridade" de decidir sobre a guarda dos filhos ou "pupilos", caso os pais ou tutores não correspondessem as determinações do Código.

De acordo com os artigos que compõem o Capítulo V do Código, o pai, a mãe ou o tutor seriam "condenados por crime contra a segurança da honra e honestidade das famílias", sendo retirado o direito do pátrio poder quando foram constatadas as práticas de castigo indevidas contra os filhos, que seja registrado ações "contra a moral e os bons costumes", ou que outras práticas que comprometiam a segurança e proteção do menor seja efetivadas. Nesse processo, o juiz de me- nores ou o tribunal, seriam as autoridades responsáveis para que as medidas fossem tomadas.

Analisar o papel do juiz de menores é necessário, uma vez que ele passava a assumir a responsabilidade de conduzir e deliberar sobre os processos das crianças e jovens. Defesa, proteção e assistência formavam o tripé que sustentava a função sóciopolítica do juiz de menores. De acordo com o jurista carioca Lemos Brito,

O papel do juiz de menores na regeneração da infância e adolescência desamparada, pervertida ou criminosa, é importantissimo, cumprindo-lhe ocupar-se do menor, desde que é apresentado em juizo, até depois que salve da escola preventiva ou reformatória (BRITTO: 1929, p. 2).

O comentário do jurista nos leva a perceber que o discurso da regeneração permeou os debates acerca do Código de Menores de 1927. A partir de uma análise do seu discurso, percebemos como a construção da ideia de que, através do Código e da ação efetiva do juiz ou tribunal, crianças e jovens que representassem ameaça ao poder político-econômico instituído pudessem ser "recuperadas socialmente". Nessa ótica, na falta de uma proteção dos pais ou tutores, cabia ao juiz de menores a decisão de encaminhá-los para as colônias ou escolas correcionais construídas pelos governos estaduais para abrigar as crianças e jovens.

O Código representou uma tentativa dos grupos sociais e econômicos estabelecidos e do Estado em centralizar e fortalecer sua ingerência sobre as famílias, transferindo para juiz de menores o poder de decidir sobre as questões pertinentes aos destinos dos “menores". Para o historiador Jacques Donzelot, "a utilização de uma única codificação, de uma etiologia homogênea, dava ao juiz um instrumento decisivo para abarcar crianças-problema de todos os pontos de vista" (DONZELOT, 2001, p. 135). 
Ao se voltar para a questão dos tutores, o Código de Menores de 1927 passou a confiar ao juiz ou tribunal, o direito da remoção da tutela e a indicação de outros responsáveis. Como nos aponta o Artigo 53: "A autoridade judicial pode, a todo tempo, substituir o tutor ou guarda do menor, ex-officio, a requerimento do Ministério Público ou das pessoas às quais aquele for confiado". (BRASIL, 1927).

Retirados da guarda dos pais ou tutores, os menores podiam ser conduzidos para as escolas correcionais, também conhecidas como institutos disciplinares, onde eram vivenciadas as práticas de uma educação profissionalizante, ensinadas as práticas agrícolas ou as artes de ofícios, como a carpintaria e marcenaria. De acordo com os estudos de Irma e Irene Rizzini, foi nesse contexto que surgiram as primeiras instituições correcionais no Brasil, que eram destinadas para abrigar as crianças e jovens que viviam na situação de abandono e ou da delinquência (RIZZINI, \& RIZZINI: 2004).

\section{Grilo e o Recife desencantado: meninos no mundo do trabalho}

O que esse espaço de trabalho, de moradia, de convívio podia possibilitar para as crianças e adolescentes que lá transitavam? Não é difícil imaginarmos que, nas ruas, essas crianças vivenciaram as mais diferentes experiências que ficaram marcadas nas suas vidas. Perambulando pelas ruas do Recife, o nosso Grilo ouviu o som do frevo. Era o ensaio do Clube Carnavalesco Carvoeiro. O pequeno foi atraído pela música, incorporou-se à multidão e caiu no passo. De repente, um senhor o convidou para conduzir a máquina de carbureto durante aquele momento, que garantia a festa da multidão. Ao aceitar, o menino Gregório acompanhou
Marchas de frevos, vivos, bonitos e ritmados, arrastando uma gigantesca multidão de improvisados foliões, uns calçados e regularmente vestidos, outros descalços, maltrapilhos e famintos; uns embriagados pelo álcool e outros pela loucura do passo e do frevo (BEZERRA, 1979, p. 117).

Era o frevo pernambucano, aquele que contagia aqueles que o escutam e o carnaval, "uma festa querida por todos", como dizia Mario Sette (SETTE, 1981). Os passos do frevo, "ao som dos clarins de momo", fizeram Gregório entrar no bloco, cair no passo, esquecer os problemas e abrir alas para um momento de alegria. Viver na rua não quer dizer que tudo é tristeza, assim afirmou Gregório ao relembrar a sua infância. Gregório sentiu-se inserido, partícipe daquele momento. Ainda aproveitou para ajudar os organizadores do Clube, garantindo um pequeno "trocado" que o fez comprar algo para comer. Depois de cair na folia, Grilo descansou e dormiu na calçada de uma casa comercial.

Em suas memórias, Gregório narrou seus sentimentos, suas emoções, sem desprezar acontecimentos que surgiram no cotidiano, chamando-nos a atenção para as histórias de nossas vidas, que também são construídas a partir do não programado, do não estabelecido, do não esperado. A partir desse depoimento, percebemos que a história se constrói no dia a dia, transforma-se a partir dos anseios, das angústias e da necessidade de resistência sentida por homens e mulheres comuns. De acordo com a historiadora Maria Izilda Matos, ao se preocupar com o cotidiano, o historiador "pretende perceber suas mudanças e permanências, descontinuidade e fragmentação, as amplas articulações, as infinitas possibilidades dessa trama multidimensional, que se compõem e recompõem continuamente" (MATOS, 2002, p. 27).

Nas ruas, Grilo passou a vender jornais. A efervescência econômica e cultural do Recife se refletiu no 
campo da imprensa escrita, quando, nesse período, o número de jornais que circulavam na cidade era bastante expressivo. Além do Jornal do Commércio e do Diário de Pernambuco, eram distribuídos o Jornal Pequeno, Pernambuco, A Província, Diário da Manhã, entre outros. Esses periódicos eram considerados progressistas ou conservadores, organizados por intelectuais ou por grupos políticos organizados. Através das páginas desses jornais, a vida da cidade era diariamente registrada.

Além dos redatores, fotógrafos e revisores, os gazeteiros se tornavam imprescindíveis para a viabilização do trabalho, uma vez que eles eram encarregados de distribuir e comercializar os jornais nos mais distantes e diferentes locais da cidade. Os vendedores de jornais dinamizaram o mundo do trabalho, proporcionando um novo campo de sustentabilidade social e econômica voltado para um número expressivo de pessoas que não tiveram oportunidade de estudar ou de se profissionalizar.

Caminhavam sob o calor do sol ou do frio da madrugada, nos distantes itinerários a pé, carregando debaixo dos braços exemplares dos jornais. Para chegar ao encontro dos consumidores, eles circulavam pelas ruas e avenidas da cidade, estabeleciam seus pontos nas esquinas, enfrentando os momentos de disputas gerados pela concorrência desenfreada, ou de alegrias, promovidas pelas vitórias conquistadas...

O território dos gazeteiros não era ocupado apenas pelos homens "feitos". Para atender à demanda de trabalho, os adultos passaram a disputar o espaço de trabalho com chamados "pequenos jornaleiros". Crianças e jovens que, em média, possuíam a faixa etária entre dos 10 aos 18 anos de idade. Analfabetos, pretos ou pardos, naturais de Pernambuco, moradores dos bairros periféricos do Recife. Muitos possuíam famílias, outros viviam o estado de abandono, adotados pelo mundo da marginalidade e da exclusão. ${ }^{1}$

Cada gazeteiro em seu setor: essa era uma regra que deveria ser respeitada, caso contrário, as disputas passavam a ser construídas no campo das agressões físicas ou verbais. Uma vez ultrapassados os limites estabelecidos, as perseguições eram efetivadas. De acordo com Gregório, a sua condição de criança fazia-o merecer uma atenção especial dos leitores e isso aborrecia outros gazeteiros, fazendo com que o "pequeno jornaleiro" fosse alvo dos chutes, dos tabefes e de outras formas de violência. Contudo, Gregório afirmava:

\begin{abstract}
Aos poucos, com muitas desvantagens contra mim, ia revidando os insultos, os palavrões, os murros, os tapas, as tabicas (...) Desgraçadamente eu era menor que os meus agressores, tinha menos força e menos agilidade do que eles, mas era teimoso, não entregava os pontos e não dava por vencido. Às vezes, com um rival eu brigava três, quatro vezes, até sentir que tivera algumas vantagens ou que ele desistia de me perseguir. Esta minha atitude impôs respeito (BEZERRA, 1979: 127).
\end{abstract}

Para Gregório, a estratégia de resistência foi construída na luta diária, na persistência, na teimosia de querer continuar vivendo. Enfrentar os riscos e desafiar o perigo nas ruas, esquinas e praças da cidade, onde cada um desses espaços físicos era dominado por grupo ou por um gazeteiro veterano, passou a fazer parte da sua rotina diária. Na luta pela sobrevivência, as negociações, os vários momentos de sujeição, o silêncio se traduziram como estratégias de resistência.

\footnotetext{
${ }^{1}$ Estes dados foram encontrados nos Livros de Entrada e Saída de Presos da Casa de Detenção do Recife que se encontram sob a guarda do Arquivo Público de Pernambuco Jordão Emereciano - Apeje.
} 
Contudo, Gregório também nos fala das redes de solidariedade que foram construídas no cotidiano. Além da atenção dos clientes e de algumas famílias que demonstravam interesse em acolhê-lo, alguns dos jornalistas apresentavam-se indignados com a exploração vivida pelas crianças e jovens. Este depoimento nos faz observar que a história dos "pequenos jornaleiros" também foi marcada pelos momentos de trocas de afetividade, pelas vitórias conquistadas, pelos fatos inusitados ocorridos na sutileza do convívio social.

As disputas por espaços passaram a fazer parte do cenário da cidade, as rivalidades entre os gazeteiros despertaram a atenção de algumas autoridades responsáveis pela segurança pública. Desse modo, as diversas notas de jornais denunciavam os momentos de violência vivenciados entre as crianças e jovens. Vejamos o diz nota publicada em 03 de maio de 1927, no Jornal do Commércio:

Entre gazeteiros - discutiam e um saiu as pauladas

Anti-hontem, pela 7 horas, na praça da Independência, o gazeteiro Augusto Ferreira, de 14 anos de idade, após discutir com seu companheiro, foi pelo mesmo agredido, recebendo várias pauladas. $O$ criminoso, preso flagrante delito, foi levado para a Delegacia de Polícia do $1^{\circ}$ Distrito da Capital. Augusto, que recebeu vários ferimentos no couro cabeludo, teve curativos no posto de Assistência Pública, recolhendo-se, logo após, a sua residência, em Bomba Grande. (Jornal do Commércio c, 1927).

O caso de Augusto Ferreira nos revela como eram assistidas as crianças e jovens que sofriam agressões físicas. Essas notas eram reproduzidas pela coluna policial do Jornal do Commercio, que, por sua vez, foi criada a partir do objetivo de divulgar o cotidiano policial, construído a partir do ideário da ordem e da paz social. A polícia, que atuava diretamente com os casos que envolviam estas crianças e jovens que vendiam jornais passou a controlar, de forma efetiva, o cotidiano delas a partir de práticas de vigilância e coerção.

Os Livros de Entrada e Saída da Casa de Detenção do Recife são documentos que nos mostram como era processado o controle sobre os "pequenos jornaleiros", uma vez que nesses registros está apontada toda a dinâmica da atuação policial. Neles, estão expostos os motivos das prisões dos "pequenos jornaleiros" e observamos qual a categoria criminosa em que eles se inseriam. Tais categorias foram construídas da lógica policialesca, que, por sua vez, pertenciam ao projeto de controle social forjado a partir dos novos interesses políticos e econômicos da sociedade burguesa da época, como nos fala Chalhoub. Essas práticas de controle e coerção procuravam intervir nas mais diversas formas de luta travadas nas experiências cotidianas dos trabalhadores (CHALHOUB, 2011).

Os registros que informavam os motivos de prisão em que essas crianças e jovens se inseriam procuravam classifica-los de vagabundos, desordeiros ou gatunos. Esses adjetivos se tornavam estereótipos utilizados na identificação desses agentes, que passavam a carregar o estigma do ameaçador, lesivo e perigoso, fazendo com que se inserissem no universo social da marginalidade. Como afirma Goffman, o estigma marca a relação entre o atributo e o estereótipo, em que a sociedade passa a "categorizar as pessoas e o total de atributos considerado como comuns e naturais para os membros de cada uma dessas categorias" (GOFFMAN, 1988, p. 11).

Em maio de 1927, o editorial do Jornal do Commercio trazia o debate sobre o cotidiano dos pequenos gazeteiros e afirmava que as autoridades deveriam preocupar-se com essa categoria profissional, uma vez que a sociedade recifense estava diariamente enfrentando a onda de perigo provocada por esses trabalhadores. Os elogios aos gazeteiros que se organizam 
em seu ponto de venda estratégico são acompanhados pela crítica de algumas crianças e jovens, afirmando que:

O caso desse gazeteiro que se prostou em frente à barrica do "Jahu" a introduziu melhor o produto da venda de jornais e vem demonstrando que, na classe a que pertence, não há apenas moleques insolentes que costumem arrumar rixas, de onde é comum sair diretinho para o outro mundo (...) O gazeteiro fica, assim, ao cabo de um desses episódios sangrentos, como o typo de "caba de peia" incorrigivel. Inútil comunicar-lhe qualquer sentimento de brandura, de mansitude e de paz. Tudo isso prova que deveriam dar ao gazeteiro a assistência que eles não tem, para deixar a faca e agir só (JORNAL DO COMÉRCIO d, 1927).

A representação construída neste editorial do Jornal do Commércio sobre as crianças e jovens que vendiam os jornais no Recife, durante esse período, tidos como os "moleques insolentes", que faziam o tipo "caba de peia", ou seja, valentão, leva-nos a perceber como a imagem dos "pequenos jornaleiros" foi construída por alguns seguimentos da sociedade daquela época. Para o editorial, a imagem dos pequenos gazeteiros foi construída sob a égide das práticas desordeiras e da violência, disseminando, assim, a ideia que as crianças que transitavam no mundo da venda de jornais representavam um perigo à sociedade.

Para conter o número expressivo de crianças e jovens destinados à Casa de Detenção, vários debates foram construídos no sentido de apontar encaminhamentos para a resolução desse problema. Além dos poderes públicos, a imprensa operária passou a discutir a assistência à infância dos "pequenos jornaleiros", como nos mostra a matéria publicada no jornal Cruzada Operária. Vejamos:

\section{A Casa do Garoto \\ Antenor Nascimento}

De uns tempos para cá, depois que Jacarepaguá fundou o Retiro dos Artistas para alojar os que da ribalta saíram sem amparo na velhice, começou a prática de se fundar tudo quanto é casa. Casa do jornalista se admite, Casa do Médico igualmente, Casa do Marinheiro também. São abrigos, os retiros, aonde se acolhem os que não venceram em suas profissões. Mas, casas sem esse destino, francamente, são indemissivel. A do garoto é uma dellas. Para mim, a idéia da Casa do Garoto só teve uma vantagem: chamar a attenção do público e das classes dirigentes para a situação dos pequenos vendedores de jornais. Estes garotos passam o dia inteiro a gritar o nome das folhas, a salta pelas estribas dos bondes, onibus e automóveis. Com certeza são mal alimentados, nutrem-se de qualquer pedacinho de pão, uma frutinha comprada aos vendedores de rua, um docinho adquirido nos tabuleiros. À noite onde dormirão? Devem dormir pelas portas das redações, pelos albergues, pelos jardins, pelos cantos escuros onde guardacivil não os vá incomodar. (NASCIMENTO, 1933).

Ao analisarmos o discurso de Antenor Nascimento, percebemos que o caso dos menores gazeteiros passou a ser visto como o problema de outras categorias profissionais, como os artistas, médicos e marinheiros. A criação da Casa do Garoto foi apontada como um mecanismo de assistência institucionalizada às crianças e jovens que vendiam jornais na cidade, a exemplo do Retiro dos Artistas, construído no Rio de Janeiro.

Desse modo, através dessa reportagem, observamos que a sociedade passava a cobrar a intervenção do Estado no sentido da resolução dos problemas dessas crianças e jovens que, para vender seus jornais, muitas vezes, mal alimentadas, tinham que dormir nas ruas ou nos jardins e enfrentar as mais diferentes formas de perigo. A Casa do Garoto foi construída na década de 
1940, durante a interventoria de Agamenon Magalhães ${ }^{2}$.

Através dessa reportagem também podemos analisar as condições de trabalho dessas crianças e jovens, quando não possuíam uma carga horária fixa, podendo trabalhar mais de 12 horas por dia, recebendo injustas comissões e tendo que andar a pé ou circular entre os transportes coletivos, abordando os passageiros. Caminhavam sob o calor do sol ou do frio da madrugada, nos distantes itinerários a pé, carregando debaixo dos braços exemplares dos jornais. Para chegar ao encontro dos consumidores, eles circulam pelas ruas e avenidas da cidade, estabeleciam seus pontos nas esquinas, enfrentando os momentos de disputas gerados pela concorrência desenfreada e as mais diferentes momentos de risco, gerado pelo simples ato de caminhar nas ruas da cidade que crescia.

Grilo, Augusto e tantos outros... As ruas da cidade do Recife são como cenários que abrigam as mais diferentes histórias de vida. Crianças e jovens que integravam o cotidiano da cidade e passaram a ser observados como por alguns setores da sociedade como indivíduos ameaçadores, que precisavam ser controlados, vigiados e disciplinados. Mas, a cidade também era deles e os espaços onde eles atuavam foram reapropriados por esses pequenos moradores, pequenos trabalhadores, fazendo com que novas maneiras de fazer a vida fossem inventados e reinventados no cotidiano. De acordo com Certeau, essas "maneiras de fazer constituem as mil práticas pelas quais usuários se apropriam do espaço organizado" (CERTEAU, 1994, p.41).
As memórias de infância de Gregório Bezerra nos fazem ouvir o som do frevo rasgado, cantado pelo Clube Carnavalesco Carvoeiro, faz-nos sentir o medo de andar pelas ruas estreitas, iluminadas por lâmpadas amareladas... Tais relatos construíram um Grilo lutador, que desafiava os perigos da grande cidade, que enfrenta a rotina diária com a vontade de vencer. Nesse jogo de imagens e representações, Gregório construiu a ideia de um personagem chamado Grilo, levando-nos a tentar encontrar os sinais de outras crianças que vivenciaram o universo social marcado pela constante relação entre a exclusão e a resistência.

As memórias de Gregório nos levam a encontrar outros indícios que nos permitem discutir como as relações entre estas crianças e jovens no mundo do trabalho, que estavam inseridos no contexto das diferentes contradições urbanas e desigualdades sociais. Através de seus relatos, podemos vislumbrar que andar pelas ruas do Recife, no início do século XX, era se deparar com as cenas de meninos vendendo jornais, pedindo esmolas, dormindo pelas calçadas, ou envolvendo-se em brigas. Essas e outras cenas foram relatadas por Gregório no sentido de relembrar o seu passado em forma de protesto.

Analisar as memórias de infância de Gregório Bezerra nos faz conhecer a visão de um depoente profundamente envolvido com contexto social e político por ele vivido, uma vez que o período em que Gregório escreveu suas memórias foi marcado por sua militância no Partido Comunista do Brasil e por toda sua trajetória de luta. Gregório construiu sua autorrepresentação de si, através do sentimento de um militante. Relembrar o passado, para Gregório, era protestar contra as injusti-

\footnotetext{
${ }^{2}$ Não podemos deixar de registrar que, em outros estados, também foram construídas instituições denominadas Casa do Pequeno Jornaleiro. O surgimento de tais instituições deve ser analisado a partir dos cenários político, social e econômico do Estado Novo, período da História do Brasil e de Pernambuco, que as políticas de assistência às crianças que viviam no mundo do trabalho adulto. Sobre o processo de construção de políticas assistencialistas ver: MIRANDA, Humberto. Meninos, moleques, menores... Faces da infância no Recife (1927 - 1937). Recife, Dissertação (Mestrado), Programa de PósGraduação em História da Cultura Regional/ Universidade Federal Rural de Pernambuco, 2006.
} 
ças sociais por ele vividas e reafirmar que, desde criança, foi envolvido com a luta pela sobrevivência.

Contudo, não podemos negar que as memórias de infância de Gregório representam uma fonte riquíssima para o historiador que pretende analisar a cidade a partir do olhar de quem viveu nas suas periferias. Ao afirmar que "na cidade dos meus encantos havia muita pobreza, miséria e sofrimento...", Gregório Bezerra me levou a encontrar os caminhos dos guetos, as palafitas, aos mocambos, sem deixar de dar o brilho da indisciplina, das festas, da trampolinagem, que se revestem como forma de resistência. A cidade de Gregório foi pintada com as cores da alegria de sobreviver aos desafios impostos pelas contradições sociais de um Recife (des) encantador.

Penso a infância como uma construção cultural historicamente demarcada. Para a sociedade ocidental moderna a infância se construiu a partir de um "sentimento" que existe um mundo particular da criança e que este deve ser respeitado. Logo, a infância é sinonímia de viver experiências sociais demarcadas culturalmente, assim afirmou o historiador francês Philippe Ariès (ARIÈS, 1981).

Ao analisar a trajetória de vida de Grilo, das crianças e dos adolescentes faz-me questionar o termo "trabalho infantil" bastante utilizado nos dias de hoje. Penso que o labor noturno e insalubre, que expõe as crianças às concorrências desenfreadas e que se desdobram em diferentes formas de violência não pode ser considerado "trabalho infantil" e sim exploração dos adultos sobre as crianças e os adolescentes.

Penso que o enfrentamento de tal exploração também deve se preocupar com a problematização do conceito, que necessita ser (re)pensada. Desse modo, o trabalho doméstico não é trabalho infantil e sim de adulto. Carregar frete nas feiras não é trabalho infantil e sim de adulto. A comercialização de jornais não é trabalho infantil e sim de adulto.

Aprendi com as histórias de vidas desses meninos e meninas que é importante questionar o conceito de "trabalho infantil", que, por sua vez, foi historicamente construído. As experiências laborais vividas por Grilo e por outras crianças não foram criadas para o mundo infantil e sim para o universo dos adultos, logo, é importante tencionar o conceito, colocá-lo na seara do debate, para que possamos produzir outro horizonte de análise intelectual e política sobre a exploração das crianças no mundo do trabalho adulto, apontando encaminhamentos para a efetiva abolição deste problema histórico.

As crianças que tiveram suas vidas narradas nesta trama historiográfica não vivenciaram as experiências do mundo do trabalho por opção e sim por que foram levadas por diferentes motivos a circularem nas casas e ruas da cidade sendo exploradas pelos adultos. A partir das diferentes trajetórias, foi possível produzir a história da exploração do mundo adulto sobre a vida dessas crianças.

\section{Considerações Finais}

A trajetória de criança do político pernambucano Gregório Bezerra é narrada a partir do discurso da superação e da sobrevivência. As experiências da violência que se encontram nas casas e nas ruas e as disputas por espaços a partir da competição dos gazeteiros foram relatadas a partir do discurso da resistência de um político, que, ao produzir um discurso sobre si, construiu uma representação das diferentes formas de violências, promovida por "sistema opressor", que negava os direitos dos filhos da "classe trabalhadora". 
Após análise dos relatos de memórias percebi que Grilo foi um personagem criado pelo Gregório para narrar as suas memórias de criança na cidade do Recife. Nas memórias do tempo de menino, as questões sociais foram desenhadas a partir da crítica social, da diferentes denúncias de exploração da mão de obra de crianças, que, ao adentrarem no mundo do trabalho adulto, tiveram suas infâncias perdidas.

As memórias produzidas sobre a trajetória do pequeno Grilo é a história de muitos meninos e meninas que vivenciam o mundo do trabalho adulto. A exploração por diferentes formas de violência marcaram as trajetórias de muitas crianças e adolescentes.

Ao produzir o entrecruzamento das trajetórias de vidas, afirmo que as histórias das crianças que tiveram suas vidas marcadas pela experiência do trabalho adulto, foi fortemente marcada por diferentes formas de violência. A exploração da mão de obra de crianças se desdobra em agressões físicas, exploração sexual, diferentes modos de tratamento cruel e degradante. Tais violências foram naturalizadas por pessoas e instituições, que buscaram produzir dispositivos de controle sobre o cotidiano desses meninos e meninas. É importante ressaltar que tais dispositivos - muitas vezes -, institucionalizaram as diversas maneiras de exploração.

Grilo não estava só. Encontrou outros "gregórios" que também foram desafiados a enfrentar a exploração do trabalho adulto. Augusto, Maria e Priscila, além de outras crianças e adolescentes, também vivenciaram experiências de violência. A trajetória de Gregório e dessas crianças me motivou a pesquisar e problematizar outras trajetórias de crianças que vivenciaram, no Recife, a experiência do labor que se desdobrou na perda de suas infâncias. 


\section{Referências}

ARIÈS, Philippe. História Social da Criança e da Família. 2ª Ed. Rio de Janeiro: LTC, 1981.

BEZERRA, Gregório. Memórias: primeira parte 100-1945. Rio de Janeiro: Civilização Brasileira, 1979.

BRASIL. Código de Menores. Rio de Janeiro, 1927.

CETEAU, Michel. A invenção do cotidiano: artes de fazer. 11ª Ed. Petrópolis: Vozes, 1994.

CHALHOUB, Sidney. Trabalho, lar e botequim. $2^{\mathrm{a}}$ Ed. Campinas: editora da Unicamp, 2001.

DIÁRIO DE PERNAMBUCO a. Menor desaparecida. Factos diversos. Recife, 08 de janeiro de 1931.

DIÁRIO DE PERNAMBUCO b. Fugiu da casa dos patrões. Factos diversos. Recife, 13 de fevereiro de 1931.

DIÁRIO DE PERNAMBUCO c. Menor encontrada. Factos diversos. DIÁRIO DE PERNAMBUCO. Recife, 18 de janeiro de 1931.

DONZELOT, Jacques. A polícia das famílias. $3^{\circ}$ Ed. Rio de Janeiro: Edições Graal, 2001.

FERNANDES, Eliane. Entrevista de Gregório Bezerra. Programa de História Oral da Fundação Joaquim Nabuco. Recife: Fundaj, 1982.

GOFMAN, Erveing. Estigma: notas sobre a manipulação da identidade deteriorada. Rio de Janeiro: LTC, 1988.

GOMES, Ângela de Castro. Escrita de si, escrita da História. Rio de Janeiro: Editora FGV, 2004.

JORNAL DO COMMÉRCIO a. Um menor que promete. Na polícia e nas ruas. Recife, 30 de janeiro de 1930.

JORNAL DO COMMÉRCIO b. Onde esta elle? Um menor desapareceu da casa dos pais. Na polícia e nas ruas. Recife, 01 de março de 1929.

JORNAL DO COMMÉRCIO c. Entre gazeteiros: discutiam e um saiu a pauladas. Na polícia e nas ruas. Recife, 03 de maio de 1927.

JORNAL DO COMMÉRCIO d. Dia a dia. Recife, 03 de maio de 1927.

LE GOFF, Jacques. Memória. V. II. Lisboa: Edições 70, 2000.

MATOS, Maria Izilda Santos. Cotidiano e cultura: história, cidade e trabalho. Bauru: Edusc, 2002. p. 27.

MIRANDA, Humberto. Meninos, moleques, menores... Faces da infância no Recife (1927 - 1937). Recife, Dissertação (Mestrado), Programa de Pós-Graduação em História da Cultura Regional/ Universidade Federal Rural de Pernambuco, 2006.

MOURA, Esmeralda Blanco Bolsonaro de. Meninos e meninas na rua: impasse e dissonância na construção da identidade da criança e do adolescente na República Velha. 1999. Revista Brasileira de História, São Paulo, v. 19, n. 37,1999 . p. 85-102.

NASCIMENTO, Antenor. A casa do garoto. Cruzada Operária. Recife, maio de 1933.

SETTE, Mario. Terra Pernambucana. Recife: Fundação de Cultura da Cidade do Recife; Recife, 1981. p. 177178. 